KREMER, R., SCHUBERT, J.M. e BONFÍGLIO, N.S. Criodesidratação de vísceras do canal alimentar no preparo de peças anatômicas para estudo veterinário. PUBVET, Londrina, V. 5, N. 13, Ed. 160, Art. 1081, 2011.

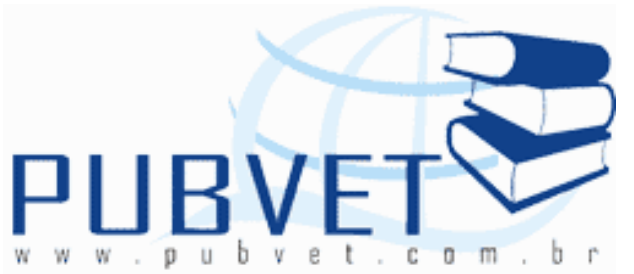

PUBVET, Publicações em Medicina Veterinária e Zootecnia.

\title{
Criodesidratação de vísceras do canal alimentar no preparo de peças anatômicas para estudo veterinário.
}

\section{Rafael Kremer $^{1}$, Jucélia Maria Schubert ${ }^{2}$, Neuranei Salete Bonfíglio ${ }^{1}$}

1 Professor de Anatomia, Universidade Regional de Blumenau (FURB), Blumenau, Santa Catarina, Brasil.

2 Técnico de Anatomia, Universidade Regional de Blumenau (FURB), Blumenau, Santa Catarina, Brasil.

\section{Resumo}

Dentre as diversas técnicas desenvolvidas para conservação de peças anatômicas, a técnica de criodesidratação no preparo de vísceras ocas é um importante procedimento, pois pode ser utilizada para auxiliar o estudo e o aprendizado de anatomia veterinária. Nessa técnica, o material é desidratado mediante a realização de congelamentos e descongelamentos, e apresenta as seguintes vantagens: fácil acondicionamento, dispensa o uso de fixadores (formol) na conservação, baixo custo da técnica, durabilidade e leveza das peças. Nesse estudo, alterações da técnica inicialmente descrita foram realizadas para melhor conservação e preservação das peças do canal alimentar. 
KREMER, R., SCHUBERT, J.M. e BONFÍGLIO, N.S. Criodesidratação de vísceras do canal alimentar no preparo de peças anatômicas para estudo veterinário. PUBVET, Londrina, V. 5, N. 13, Ed. 160, Art. 1081, 2011.

\title{
Viscera dehydration of the alimentary canal in the preparation of anatomical parts for veterinary study
}

\begin{abstract}
Among the various techniques developed for conservation of anatomical specimens, the technique of dehydration in the preparation of hollow viscera is an important procedure because it can be used to aid the study and learning of veterinary anatomy. In this technique, the material is dried by conducting freezing and thawing, and has the following advantages: easy handling, requiring the use of fixatives (formalin) in conservation, low cost of technology, durability and lightness of the pieces. In this study, changes in technique were initially described for better maintenance and preservation of parts of the alimentary canal.
\end{abstract}

\section{INTRODUÇÃO}

Anatomia é definida como a ciência que descreve a forma do ser, seu desenvolvimento, arquitetura, estrutura, situação, relação dos órgãos e o valor morfológico - razão de sua existência e a função que desempenham - do todo e suas partes. No estudo da anatomia, diversas técnicas anatômicas podem ser empregadas para conservação da estrutura do animal; possibilitado ao observador, acadêmico ou profissional, explorar e visualizar a forma do mesmo órgão de diferentes maneiras. Dessa forma, ao empregar uma técnica para conservação de determinada estrutura, podemos ter a finalidade de preservar a forma, cor, aparência, dimensões e relações dos órgãos. Além do que, deve ser analisado se a técnica possibilita o fácil acondicionamento, a inutilização de fixadores (formol) na conservação e manutenção, o baixo custo para execução, a durabilidade e o peso das peças (RODRIGUES, 1973; MIRANDA-NETO, 1990; DI DIO, 2002).

TEIXEIRA et al. (1991) e TEIXEIRA et al. (1996), descreveram uma nova técnica de conservação de estruturas anatômicas através da desidratação de 
KREMER, R., SCHUBERT, J.M. e BONFÍGLIO, N.S. Criodesidratação de vísceras do canal alimentar no preparo de peças anatômicas para estudo veterinário. PUBVET, Londrina, V. 5, N. 13, Ed. 160, Art. 1081, 2011.

músculos, vísceras ocas e parenquimatosas, onde as estruturas foram congeladas e descongeladas repetitivamente. A base desse procedimento de criodesidratação consiste no fato de que seções de congelamento lento $\left(-17^{\circ} \mathrm{C}\right)$ formam cristais de gelo que destroem as paredes da célula, tornando fácil a liberação de líquido intersticial e intracelular. Ao mesmo tempo, a expansão do volume da água congelada, provoca nos tecidos, microfissuras e afastamento do tecido conjuntivo, que possibilitam a eliminação da água quando a peça for descongelada.

As adaptações e variações da técnica de criodesidratação aplicadas no preparo de órgãos do canal alimentar, para o estudo em anatomia veterinária, serão aqui descritas e discutidas.

\section{DESCRIÇÃO DA TÈCNICA}

A técnica obedece à seguinte sucessão de procedimentos:

10 Procedimento - Coleta do material: A víscera oca deve ser adequadamente removida do corpo do animal. Em seguida, o tecido adjacente ao órgão, como gordura e peritônio, devem ser retirados através de dissecação grosseira. Sendo, melhor utilizar animais mais magros, pois a gordura não permite a total desidratação do órgão.

$2^{\circ}$ Procedimento - Lavagem do material: O material deve ser lavado em água corrente até a retirada completa das substâncias contidas no interior das vísceras ocas. Órgãos do canal alimentar devem ser abertos para facilitar a lavagem.

$3^{\circ}$ Procedimento - Fixação do material: Nesse momento deve-se colocar algodão ou tecido no interior do órgão do canal alimentar e condicionálo da melhor forma possível, para preservação de sua forma. Deve-se imergir totalmente o órgão em solução de formol a $10 \%$. Para facilitar a imersão total 
KREMER, R., SCHUBERT, J.M. e BONFÍGLIO, N.S. Criodesidratação de vísceras do canal alimentar no preparo de peças anatômicas para estudo veterinário. PUBVET, Londrina, V. 5, N. 13, Ed. 160, Art. 1081, 2011.

da peça, deve-se colocar algodão ou tecido sobre a mesma. O tempo de permanência no formol dependerá do tamanho do órgão. Por exemplo, o estômago do cão deverá permanecer imerso por 2 a 3 dias, enquanto que o do ruminante de 10 a 15 dias. Peças frescas são melhores na manutenção da forma.

40 Procedimento - Período pré-desidratação: Após a fixação, o material deve ser lavado em água corrente e a dissecação mais minuciosa da peça deve ser iniciada (não havendo necessidade de ser completada nessa etapa). Deve-se renovar o algodão ou tecido no interior do órgão. O material poderá ser acondicionado em vasilhames plásticos, tomando cuidado para não amassá-lo.

$5^{\circ}$ Procedimento - Período de desidratação $\left(-17^{\circ} \mathrm{C}\right)$ : A peça preenchida com algodão deve ser envolta em sacos plásticos escuros e ser submetida a seções de congelamento em "freezer" na temperatura de $-17^{\circ} \mathrm{C}$ e descongelamento em temperatura ambiente. No descongelamento, a peça retirada do freezer, poderá ser pendurada para escorrimento da água descongelada. Nessa fase, a peça não deve ser exposta ao sol e vento ou ficar muito tempo fora do "freezer" (somente até descongelar), pois os mesmos promovem o ressecamento excessivo da peça. Quando a peça perder aproximadamente $70 \%$ de seu peso ela estará pronta. Durante o descongelamento da peça pode ser pincelado glicerina para amaciar a peça, entretanto a mesma apresentará coloração mais escura.

$6^{\circ}$ Procedimento - Envernizamento do material: Como procedimento final a peça deverá ser envernizada. Recomenda-se a utilização de verniz fosco em "spray", onde deverão ser aplicadas finas camadas com intervalos de secagem. 
KREMER, R., SCHUBERT, J.M. e BONFÍGLIO, N.S. Criodesidratação de vísceras do canal alimentar no preparo de peças anatômicas para estudo veterinário. PUBVET, Londrina, V. 5, N. 13, Ed. 160, Art. 1081, 2011.

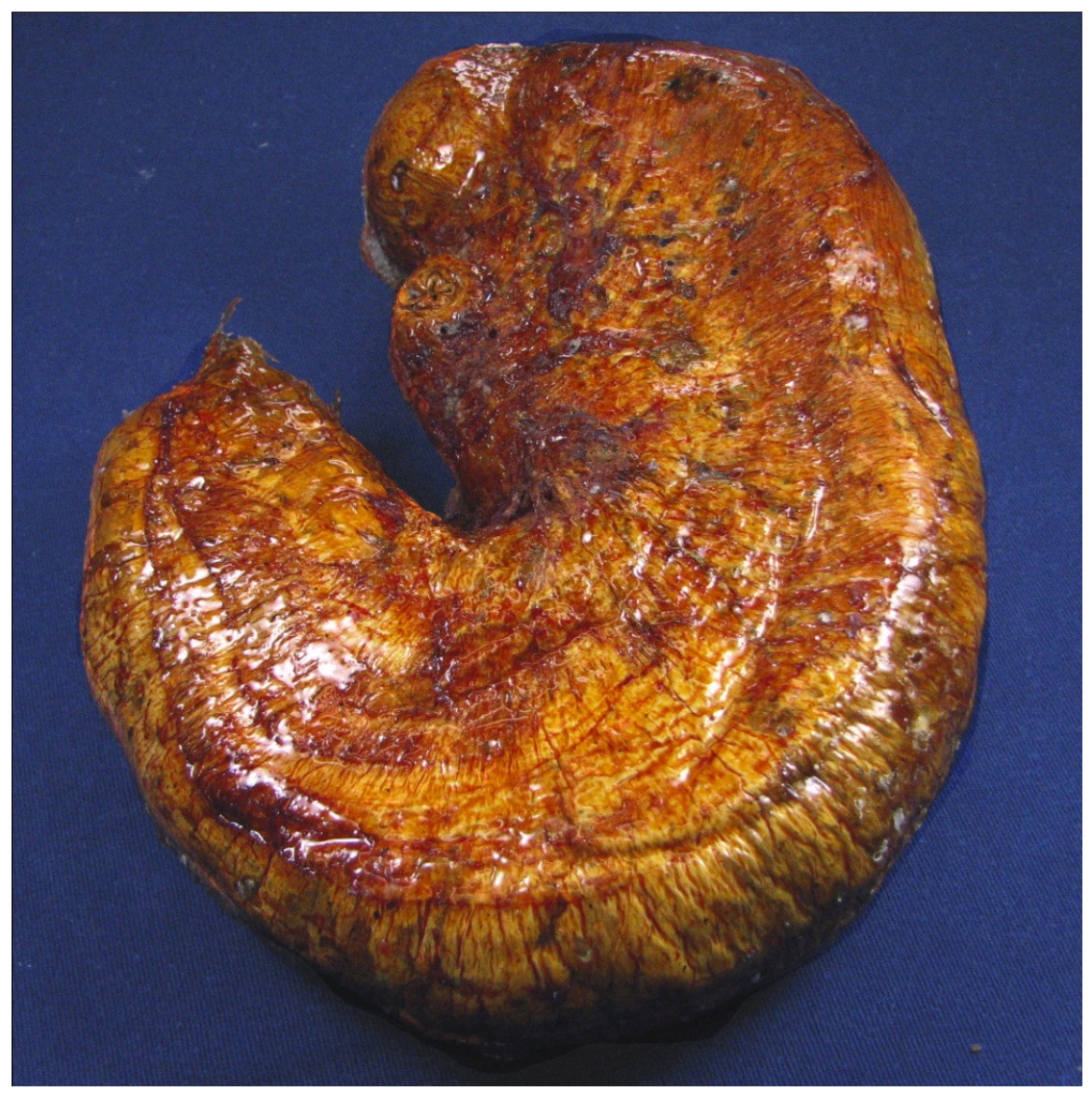

Figura 1 - Criodesidratação de vísceras do canal alimentar de porco para preparo de peças anatômicas para estudo veterinário.

\section{DISCUSSÃo}

A criodesitratação é uma técnica antiga que utiliza seções de congelamento e descongelamento para obter peças anatômicas conservadas sem odor, leves e de fácil utilização em laboratórios de anatomia. A técnica é baseada no princípio de que o congelamento lento da água no interior da célula, causa sua expansão e forma cristais de gelo grandes o suficiente para romper a membrana plasmática celular. Através de repetições do procedimento um número maior de rupturas acontece na parede celular, facilitando a liberação de água do tecido (HINER \& HANKINS, 1947; KOONZ \& RAMSBOTTON, 1939) 
KREMER, R., SCHUBERT, J.M. e BONFÍGLIO, N.S. Criodesidratação de vísceras do canal alimentar no preparo de peças anatômicas para estudo veterinário. PUBVET, Londrina, V. 5, N. 13, Ed. 160, Art. 1081, 2011.

Essas microrupturas, segundo TEIXEIRA et al. (1996), causam retração tecidual. Em nossas peças a retração tecidual foi minimizada através da adição de algodão no interior das cavidades das vísceras, uma vez que o algodão impediu a perda do volume do órgão por retração. A colocação da peça em saco plástico escuro foi outra adaptação vantajosa, pois diminuiu a modificação da cor da peça, assim como, seu excessivo ressecamento.

Concordando com TEIXEIRA et al. (2006) observamos também as seguintes vantagens descritas na apresentação do método de criodesidratação de vísceras ocas: 1) eliminação do uso de fixadores nocivos á saúde; 2) facilidade no acondicionamento da peça, não havendo necessidade de guardar a peça em caixas ou tanques com fixadores; 3) a redução do peso, pois em anatomia comparada alguns animais possuem grande porte e são de difícil deslocamento e transporte; 4) pouco gasto com conservantes para preparar e manter as peças; e 5) permite dissecações e explorações mesmo depois de desidratadas.

Dessa forma, observamos que a criodesidratação, como técnica de preparação de peças anatômicas para estudo em anatomia veterinária, é uma opção de baixo custo que oferece vantagens de acondicionamento, transporte e manutenção em relação às demais técnicas tradicionais que utilizam fixadores em sua manutenção.

\section{BIBLIOGRAFIA}

HINER, R.L.; HANKINS, O.L. Temperatures of freezing affects tenderness of Beff. Food Ind., v. 19, p.1078, 1947.

KOONZ, C.H.; ROMSBOTTON, J.M. A method for studying the histological structure of frozen products. I. Poultry. Food Res., v.4, p.117, 1939.

TEIXEIRA, A.; TEIXEIRA, A.F.; GUARENTI, V.P.J. Desidratação de músculos no preparo de peças anatômicas. Rev. bras. Ciên. Morfol., v.7/8, n.2/1, p. 45-47, 1990-1991.

TEIXEIRA-FILHO, et al. A técnica de criodesidratação aplicada em órgãos cavitários e parenquimatosos. Braz. J. morphol., n.2, p.177-180, 1996.

RODRIGUES, H. (2005). Técnicas Anatômicas.Propria: 2 ed Vitoria, 58p. 
KREMER, R., SCHUBERT, J.M. e BONFÍGLIO, N.S. Criodesidratação de vísceras do canal alimentar no preparo de peças anatômicas para estudo veterinário. PUBVET, Londrina, V. 5, N. 13, Ed. 160, Art. 1081, 2011.

MIRANDA-NETO, M.H. Sobre a utilização de adesivo à base de polivinil acetato (PVA) na preparação de ossos para estudos. UNIMAR, 1990, 87-89.

DI DIO, L. J. A. Tratado de anatomia sistêmica aplicada: princípios básicos e sistêmicos : esquelético, articular e muscular. 2.ed. São Paulo: Atheneu, 2002. 